\title{
Construction loads using a shoring-clearing-striking process
}

Isabel Gasch PhD

Engineer in Industrial Management, Institute of Concrete Science and Technology (ICITECH), Universitat Politècnica de València, València, Spain Yezid A. Alvarado $\mathrm{PhD}$

Civil Engineer, Pontificia Universidad Javeriana, Bogotá, Colombia

\section{Pedro A. Calderón PhD}

Civil Engineer, ICITECH, Universitat Politècnica de València, València, Spain

Salvador Ivorra PhD

Industrial Engineer, Departamento de Ingeniería de Construcción, Universidad de Alicante, Alicante, Spain

This paper presents the results of tests carried out during the construction of a block of flats with reinforced concrete slab floors in Madrid, Spain, using the shoring, clearing and striking process. Loads on shores were recorded during the different construction stages of floor slabs 1 to 6 . The experimental results were used to analyse load transmission between slabs and shores during the construction of the building. The results of the analysis showed that slab-shore load transmission differed according to the position of the span analysed, and also that variations in the construction process had a significant effect on the expected loads. The paper includes the evolving calculation developed using a non-linear numerical model to simulate the building's behaviour during the different construction phases and variations in concrete properties with time. Experimental and numerical finite-element model results are compared with those obtained by applying simplified methods that consider the real stiffness of the shoring.

\section{Notation}

$\bar{Q}_{\text {D\&C }} \quad$ average load per square metre on shores obtained with the improved simplified method of Duan and Chen (1995)

$\bar{Q}_{\text {exp }} \quad$ average load per square metre on shores obtained from experimental readings

$\bar{Q}_{\text {Fang }}$ average load per square metre on shores obtained with the simplified method of Fang et al. (2001a)

$\bar{Q}_{\text {FEM1 }}$ average load per square metre on shores obtained with the finite-element method (FEM) analysis 1

$\bar{Q}_{\text {FEM2 }}$ average load per square metre on shores obtained with FEM analysis 2

$\bar{Q}_{\text {NSP }} \quad$ average load per square metre on shores obtained with new simplified procedure of Calderón et al. (2011)

\section{Introduction}

Factors such as safety, execution time and cost are important considerations in the construction process. Shoring systems used in the construction of buildings with floor slabs cast in situ are expensive, so it is advisable to carefully plan their use so as to recover most of the items in the shortest possible time in order to cut costs and keep execution time to the minimum.

To obtain these objectives, the method known as clearing or partial striking is used in Spain. This technique consists of removing the formwork and $50 \%$ of the slab-supporting shores several days after casting. This considerably reduces the materials necessary for formwork and shoring, cuts costs and rationalises the building process.

Several authors have carried out research studies to determine load distributions during the construction process through the use of theoretical models (Alvarado et al., 2010; Calderón et al., 2011; Duan and Chen, 1995; Fang et al., 2001a, 2009a, 2009b; Grundy and Kabaila, 1963; Stivaros and Halvorsen, 1991) and experimental studies (Alvarado et al., 2009; Fang et al., 2001b; Moragues et al., 1991; Pintado and Carlton, 2007; Rosowsky et al., 1997). However, very few authors have studied the clearing technique.

Moragues et al. $(1991,1996)$ carried out experimental numerical studies of its effect on load transmission during the construction of floor slabs and concluded that the simplified method proposed by Grundy and Kabaila (1963) was not suitable for the particular case of clearing.

Alvarado et al. (2009) also studied the effects of the clearing process by monitoring a full-scale experimental building. From the loads recorded on the shores, they observed that after partial striking had been carried out there was a reduction of the average load per unit of area in the shoring system. However, this load reduction cannot be evaluated by the simplified methods normally used to evaluate loads on shoring.

Alvarado et al. (2010) also carried out a simulation of the experimental building using a finite-element method (FEM). In order to be able to simulate slab-shore load transmission, the FEM used considered the construction process in the experimental model as well as variations in concrete properties over time. This model was verified by the experimental results and it was, therefore, concluded that the methodology used in the FEM did in fact reflect the real conditions. 
More recently, Calderón et al. (2011) developed a new simplified procedure to estimate load transmission between shores and slabs during different construction phases; this method takes into account factors such as the evolution of concrete elasticity modulus with time and assumes finite shore stiffness. It also considers that the average deformation of the set of shores supporting a slab coincides with the average slab deformation. This new simplified procedure was validated using the periodic experimental measurements obtained by Alvarado et al. (2009) and the FEM results obtained by Alvarado et al. (2010). Additionally, the results from the procedure developed by Calderón et al. (2011) were compared with those obtained from the improved simplified procedure of Duan and Chen (1995) and the simplified method of Fang et al. (2001a, 2001b). The conclusion reached was that the new simplified procedure presented a better fit with the experimental measurements.

\section{Objectives and novelty of this study}

The present study is a continuation of previous work carried out at the Institute of Concrete Science and Technology (ICITECH) of the Universitat Politècnica de València that focused on the study of load transmission between slabs and shores during the construction process of multi-storey buildings (Alvarado, 2009; Alvarado et al., 2009, 2010; Calderón et al., 2011). The experimental studies carried out to date by Alvarado (2009) and Alvarado et al. (2009) were done under controlled conditions.

With the double aim of studying the effect of the clearing process on slab-shore load transmission in a real building under construction and the effects on this load transmission of possible variations in the construction process, the present paper describes the monitoring of the construction process in a block of flats being built with reinforced concrete slab floors in Madrid, Spain.

This paper presents the measurements carried out during construction involving the shoring, clearing and striking (SCS) process. The building was later simulated using the FEM, including the different construction phases and variations in concrete properties with time, as described in Alvarado et al. (2010). Finally, three simplified methods were applied and the results obtained were compared.

The novelty of this work is calibration of the numerical model developed by Alvarado et al. (2010). It is also the first time that the new simplified procedure of Calderón et al. (2011) has been applied to a real building and the results compared with experimental measurements

\section{Experimental study}

\subsection{The case study building}

The building, $45 \cdot 10 \mathrm{~m}$ high with four underground floors and 14 above ground levels, is located in Madrid, Spain. The height of the ground floor is $3.65 \mathrm{~m}$ and all other floors are $3.05 \mathrm{~m}$ high. The underground floors are of height $3.00 \mathrm{~m}$, except for the first level with a height of $3.43 \mathrm{~m}$. The structure consists of reinforced concrete slab floors plus non-load-bearing walls, columns and concrete beams. Concrete slabs are of varying depths on different floors, being $0.30 \mathrm{~m}$ thick in underground levels 2 to $4,0.35 \mathrm{~m}$ and $0.60 \mathrm{~m}$ in the ceiling of underground level 1 , and $0.22 \mathrm{~m}$ in the floors above ground level, except for the ceiling of the twelfth floor, which is $0.30 \mathrm{~m}$ thick. Figure 1 shows a cross-section of the studied building. The concrete used for all structural elements had a cylinder compressive strength of $25 \mathrm{MPa}$.

\subsection{Construction process}

Figures 2 to 5 show the construction process. Each slab was divided into three phases - shoring, clearing and striking. The clearing process consists of the removal of formwork, the secondary straining pieces and the shores that supported them, so that the slab was then resting on the primary straining pieces, which transmitted the load onto the remaining shores. Three sets of shores were used for the construction cycles, with one storey supported by a full set of shores while two others were supported by partial sets. The construction of each floor took 7 days.

\subsection{Monitoring}

The load transmission between shores and slabs varies according to the type of span. Researchers such as Liu et al. (1985), Duan and Chen (1995), Fang et al. (2001a) and, more recently, Calderón et al. (2011) have taken into account the different slab boundary conditions in their simplified models. Because of this, the current work studied two spans with different boundary conditions. A corner span and a border span (Figures 6(a) and 6(b)) were fitted with instrumentation; the corner span had inter-column lengths of $3.50 \times 4.50 \mathrm{~m}$ and the border span $5.40 \times 5.20 \mathrm{~m}$. Figure 6 (a) shows the arrangement of the monitored shores for level 1 , which has two secondary straining pieces. Figure 6(b) shows this arrangement for levels $2-6$, which have one secondary straining piece.

Readings were taken from the casting of the ground floor slab (slab 1) to the casting of the slab forming the ceiling of the fifth floor (slab 6). As shown in Figures 6(a) and 6(b), each span had a straining piece with six shores fitted with strain gauges plus a reference shore for each floor. A total of 39 shores were fitted with three strain gauges each (protected from contact with other objects and against damp) with an angle of $120^{\circ}$ between each one at a height of $1.25 \mathrm{~m}$. The average deformation value between the three gauges was used to establish the load to which each shore was subjected during the construction process. Reference shores were placed with the aim of measuring the effect of ambient temperature on the shores themselves, the strain gauges and the data acquisition system (see Figure 7). These shores were not subjected to loads and thus did not form part of the buildings' shoring system.

A measurement station was used to record the readings. This was composed of a network module, a data acquisition module connected to the strain gauges and a laptop computer equipped with software developed by ICITECH staff (see Figure 7). 


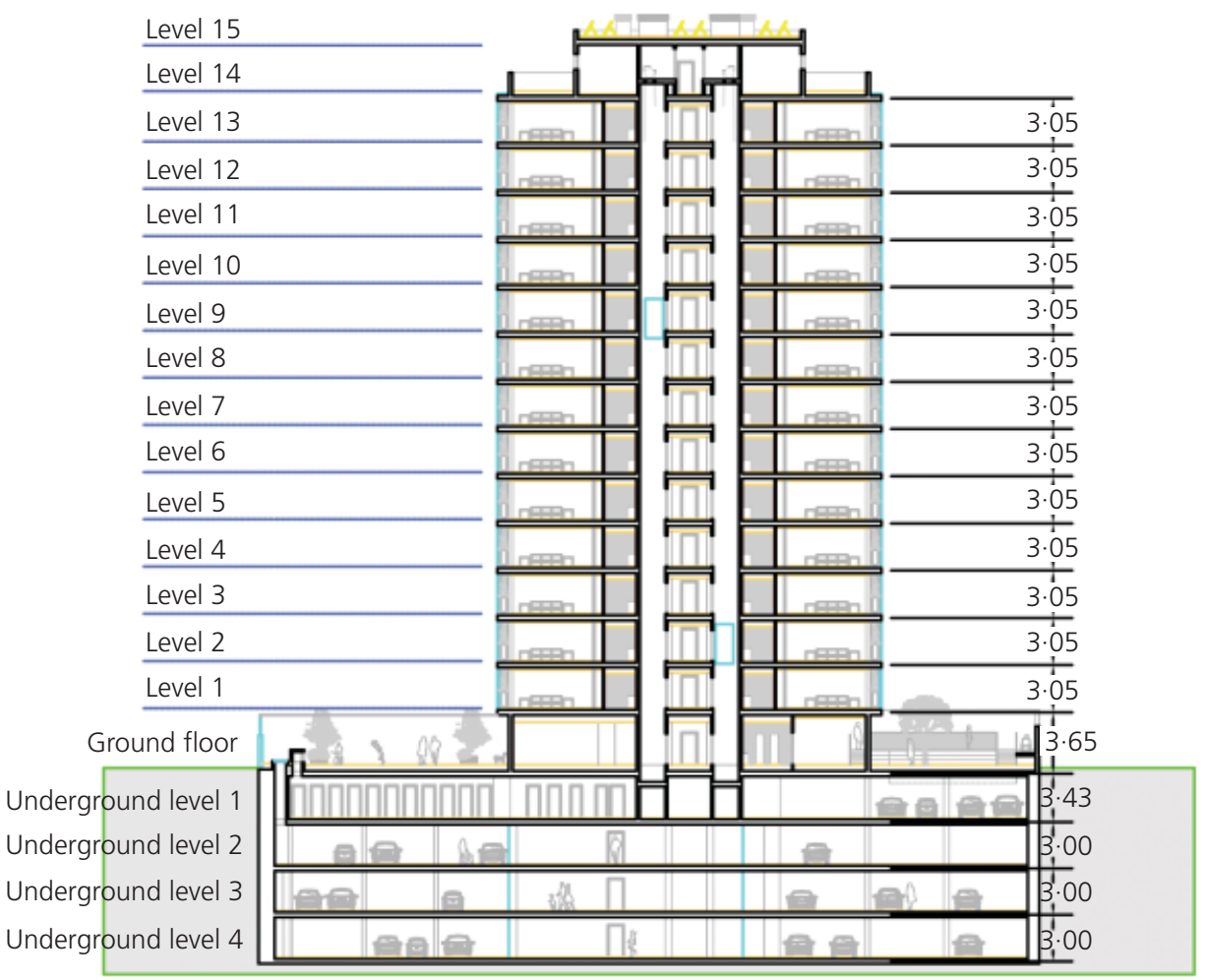

Figure 1. Cross-section of studied building (dimensions in metres)
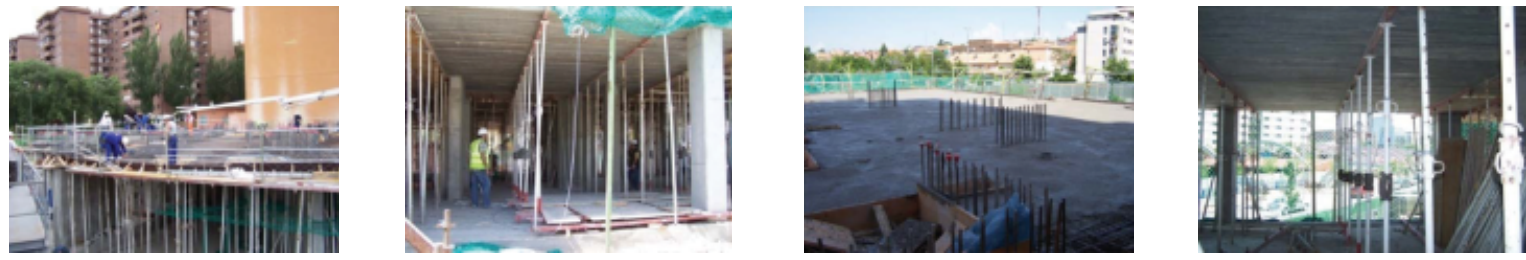

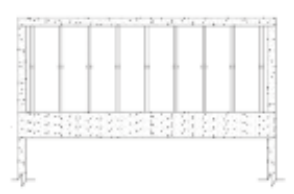

$t=0$ days

Casting of level

Load step 1

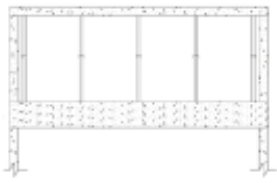

$t=7$ days

Clearing of level

Load step 2

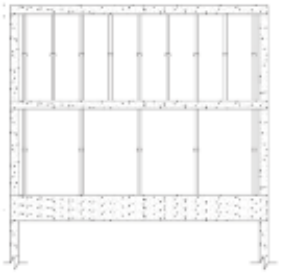

$t=10$ days

Casting of level 1 Load step 3

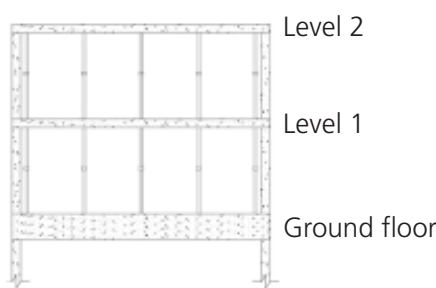

$t=15$ days

Clearing of level 1

Load step 4

Figure 2. The construction process from start to day 15

\subsection{Summary of readings}

Periodic readings were taken for each casting, clearing and striking operation, from the casting of slab 1 to the casting of slab 6. The readings were taken before and after each operation and provided information on the load increase on slabs and shores due to each operation. At that moment, no construction or live loads were present at the slabs. Table 1 gives the results obtained for each construction phase for the corner and border spans. The average load $\left(\bar{Q}_{\text {exp }}\right)$ on the shores $\left(\mathrm{kN} / \mathrm{m}^{2}\right)$ is shown for each slab and was considered to be the 

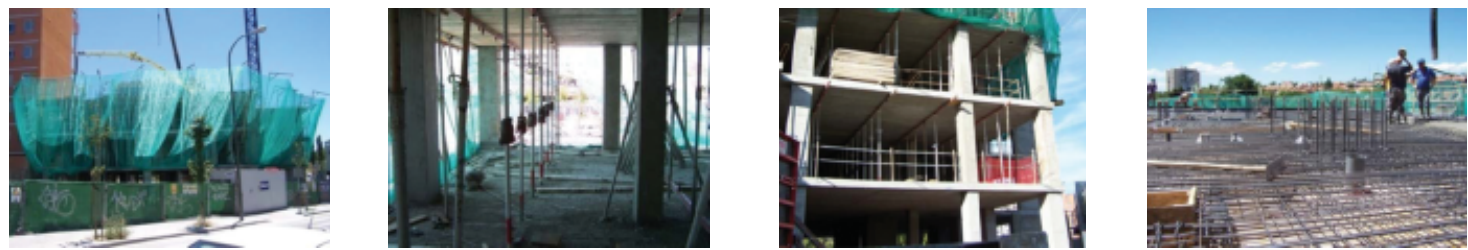

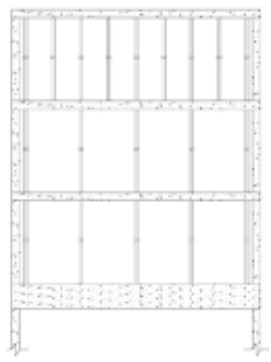

$t=16$ days

Casting of level 3

Load step 5

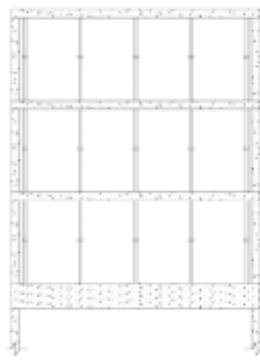

$t=21$ days

Clearing of level 3

Load step 6

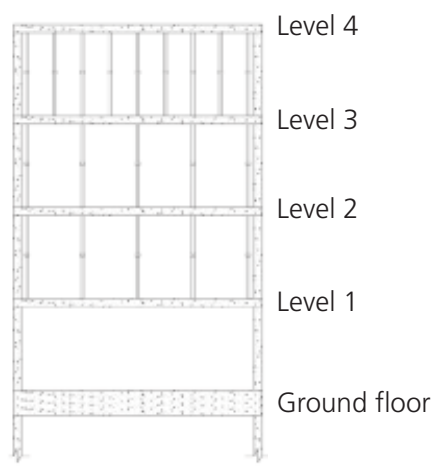

$t=23$ days

Casting of level 4

Load step 8

Figure 3. The construction process, day 16 to day 23
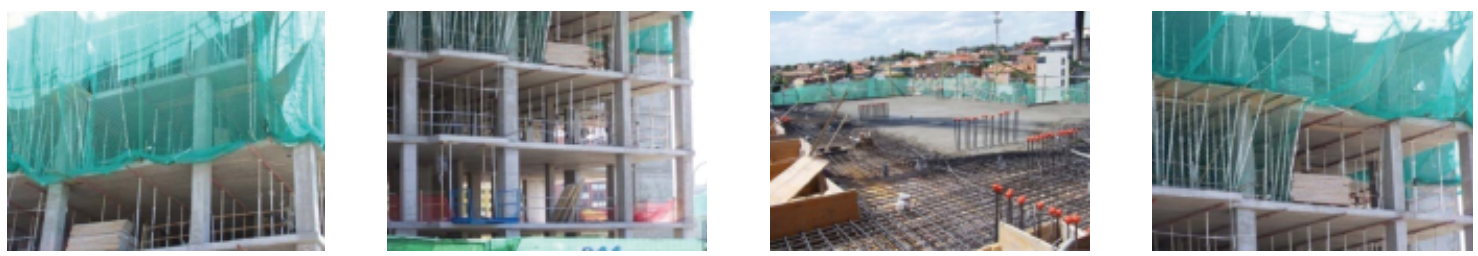

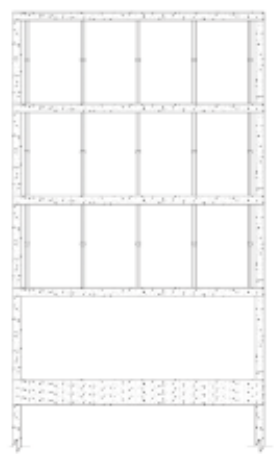

$t=28$ days Clearing of level 4 Load step 9

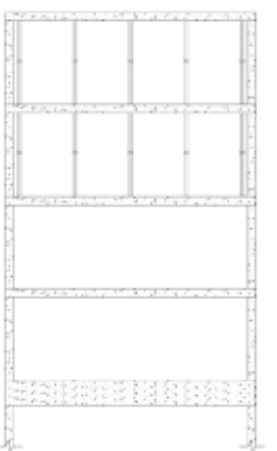

$t=29$ days Striking of level 2 Load step 10

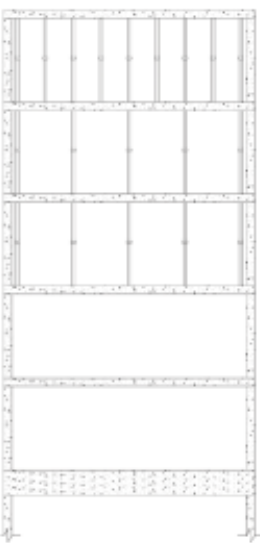

$t=30$ days Casting of level 5 Load step 11

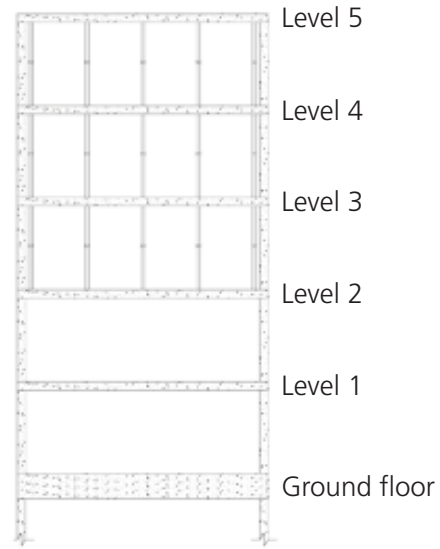

$t=35$ days

Clearing of level 5

Load step 12

Figure 4. The construction process, day 28 to day 35

sum of the total shore load divided by the total area supported by the shores.

\subsection{Analysis of readings}

The results showed that load transmission varied according to the type of span studied, due to the different ways in which their deformability and/or stiffness were affected by their different geometries and boundary conditions. The following conclusions were reached.

(a) On casting, the total slab load is transmitted to the shoring.

For example, during the casting of slab 1 of the corner span, 

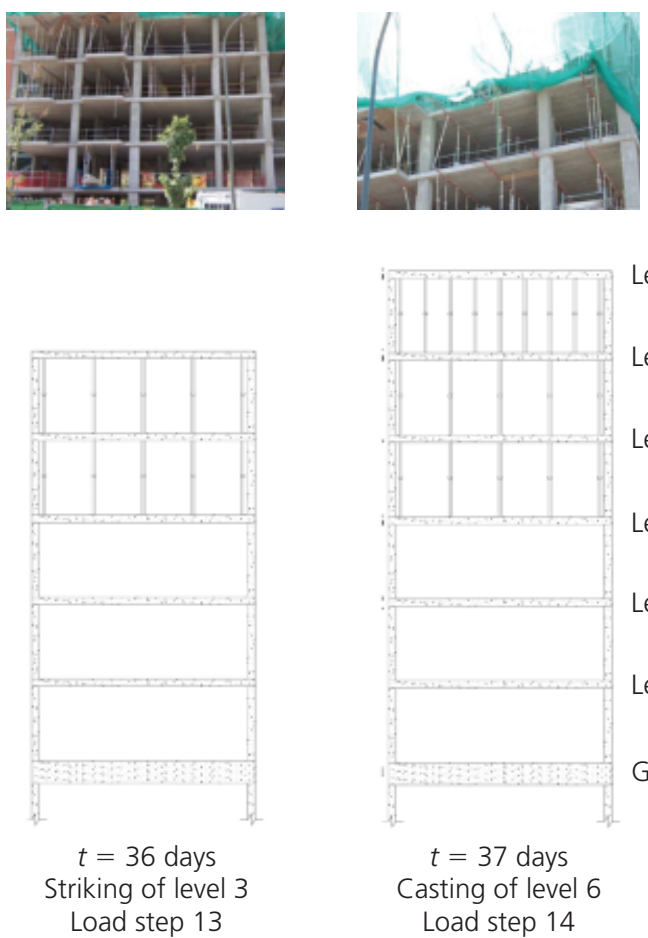

Striking of level 3

Load step 13
Level 6

Level 5

Level 4

Level 3

Level 2

Level 1

Ground floor

asting of level 6

oad step 14

Figure 5. The construction process, days 36 and 37

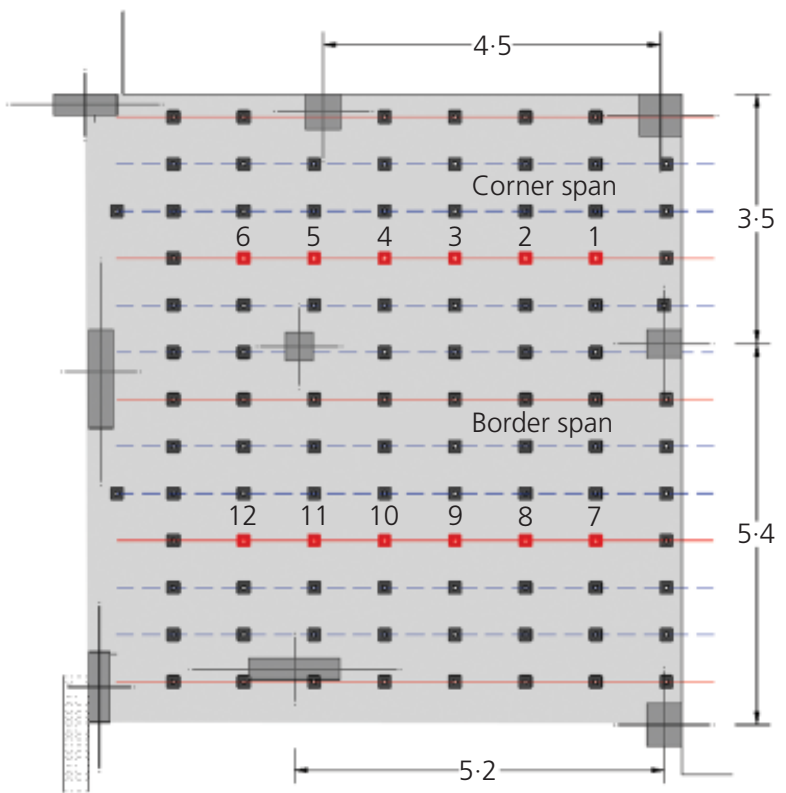

(a)

the average shore load $\left(\bar{Q}_{\exp }\right)$ was $4.95 \mathrm{kN} / \mathrm{m}^{2}$ - a value that is only $1 \%$ less than the slab self-weight $\left(4.96 \mathrm{kN} / \mathrm{m}^{2}\right)$.

Similar results were observed for the casting of the rest of the slabs and for both spans. This is a reflection of the high degree of precision of the readings taken during the construction process.

(b) For the clearing operation, the five slabs from which readings were taken assumed a considerable part of the load. It was found that the percentage load transferred to the slabs in the clearing operation varied from

(i) $48 \%$ to $64 \%$ of the slab self-weight (corner span)

(ii) $41 \%$ to $61 \%$ of the self-weight (border span).

(c) When a slab is cast, a great part of its weight is assumed by the slab immediately below, which has already been cleared. It was found that the percentage load in these cases was as follows.

(i) $72 \%, 75 \%$ and $79 \%$ of the self-weight of the recently poured upper slab in the case of casting slabs 2, 3 and 6 , respectively. In the case of the casting of slabs 4 and 5, the percentages were $94 \%$ and $91 \%$ (corner span).

(ii) $75 \%, 77 \%, 73 \%$ and $54 \%$ of the self-weight of the recently poured upper slab in the case of the casting of slabs 2, 3, 5 and 6, respectively. In the case of the casting of slab 4 , the percentage was $93 \%$ (border span).

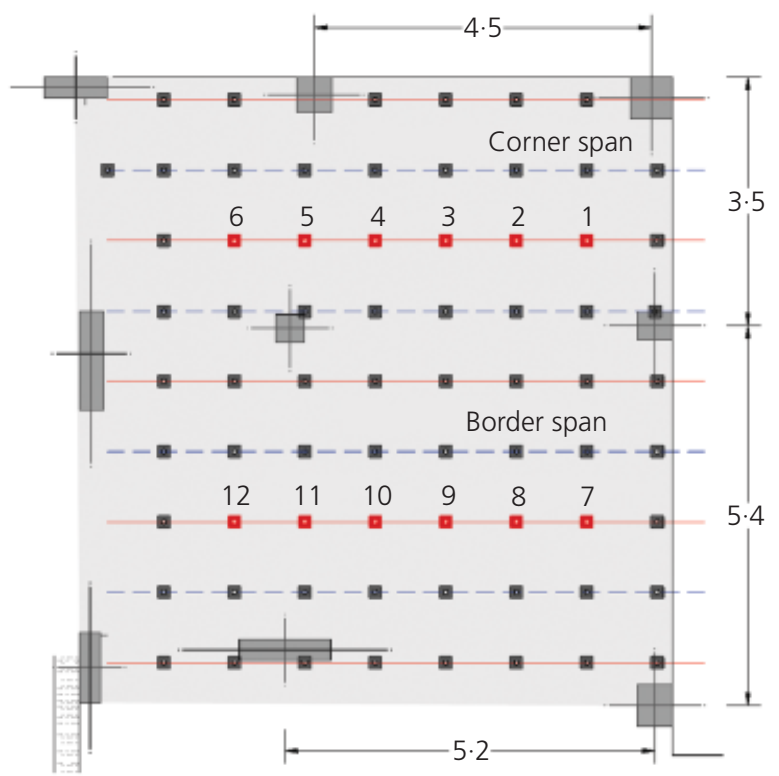

(b)

- Instrumented shore

- Non-instrumented shore

Primary straining piece

Secondary straining piece

Figure 6. Arrangement of the monitored shores: (a) level 1;

(b) levels 2-6 (dimensions in metres) 


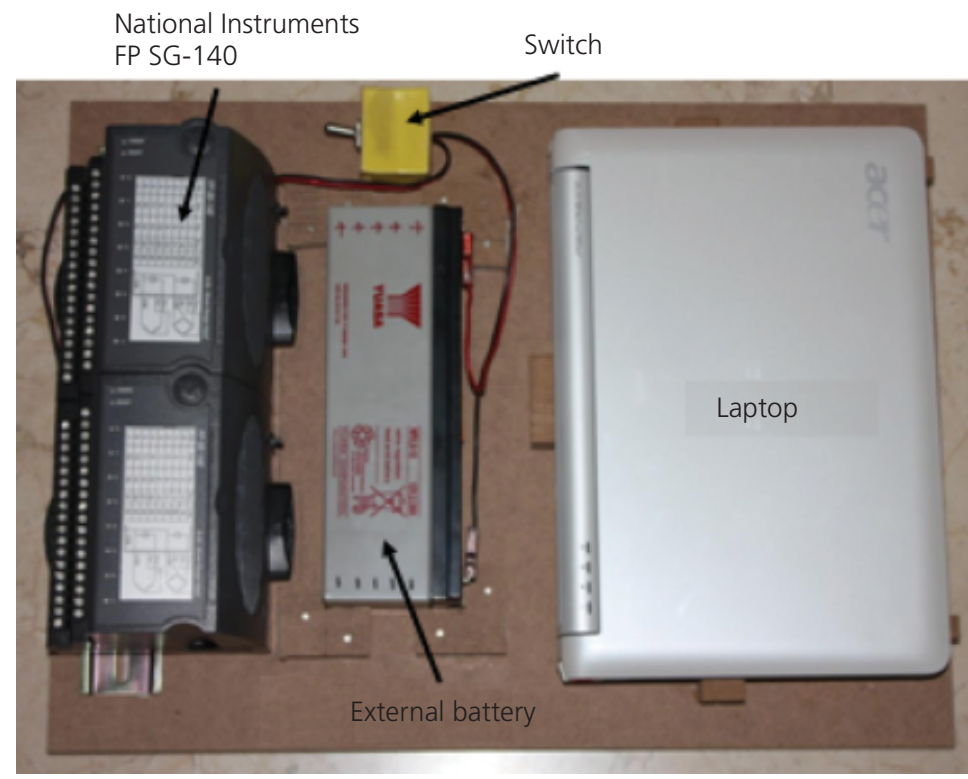

(a)

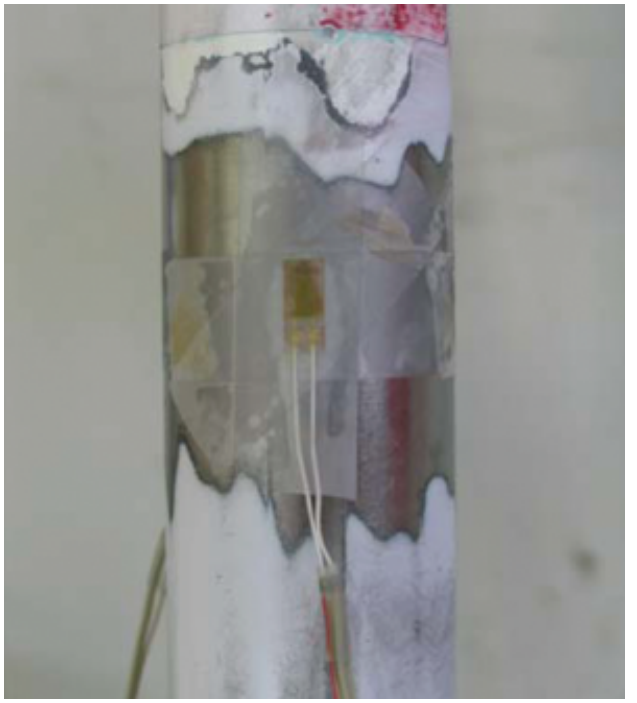

(b)

Figure 7. Monitoring system: (a) measurement station;

(b) instrumented shore

(d) When the shores are removed from under a slab, the load supported by the shores is assumed by the upper slabs through their shoring. This case study revealed the following.

(i) For the corner span, when the shores were removed from slab $1,64 \%$ of the load they had borne was assumed by slab 1 and the remaining $36 \%$ to the upper floors connected by shores. When slab 2 was struck, $73 \%$ of the weight borne by the shores was assumed by slab 2 itself and the remainder by the upper floors through their shores. On striking slab 3, 87\% of the shore load was passed to the slab and $27 \%$ was assumed by the upper floors.

(ii) For the border span, when the shores were removed from slab $1,52 \%$ of the load they had borne was assumed by slab 1 and the remainder to the upper floors connected by shores. When slab 2 was struck, $73 \%$ of the weight borne by the shores was assumed by slab 2 itself and the remaining $27 \%$ by the upper floors through their shores. On striking slab 3, 79\% of the shore load was passed to the slab and the remainder was assumed by the upper floors.

(iii) When a slab is struck, the deflection of this slab increases. This means that the load of the shores located above that slab decreases. This behaviour is the same in the upper levels and has been shown by authors such as Grundy and Kabaila (1963), Duan and Chen (1995), Fang et al. (2001a), Alvarado et al. (2010) and Calderón et al. (2011).

In summary, in all of the construction stages, the slab of the corner span supports more load than the slab of the border span.
Generally, if the distance between columns is the same in a corner and a border span, the corner span is less rigid (more deformable) than the border span. In this case, the corner span is smaller than the border span; this makes it more rigid and consequently the slab supports higher loads during the construction process.

\section{Finite-element model}

A numerical model was designed to simulate the building structure and the construction process described above. The simulation was carried out using the commercial software Ansys 11.0 (Ansys, 2006a). The procedure described by Alvarado et al. (2010) was followed, assuming a non-linear evolving calculation that considered both the construction phases and variations in the concrete mechanical characteristics in each phase.

The software (Ansys, 2006a) allows an evolving calculation to be performed by means of different load steps. A load step consists of calculating the structure with material and geometric properties corresponding to each of the building phases considered. After solving the first load step, the second load step is based on the load and deformation values obtained from the first. An evolving calculation is thus performed with a load step for each building phase. All these considerations made the FEM a non-linear geometrical model (Alvarado et al., 2010).

Since the experimental analysis was confined to a corner span and an adjacent border span, it was decided to model only part of the building. Slab continuity was simulated by cantilevers that produce a bending moment in the line of columns similar to that caused by the adjacent spans in the actual building. Figures 8(a) 


\begin{tabular}{|c|c|c|c|}
\hline \multirow{2}{*}{$\begin{array}{l}\text { Stage of } \\
\text { construction }\end{array}$} & \multirow[t]{2}{*}{ Level } & \multicolumn{2}{|c|}{ Load: kN/m² } \\
\hline & & $\bar{Q}_{\text {expcorner }}$ & $\bar{Q}_{\text {expborder }}$ \\
\hline Casting level 1 & 1 & 4.96 & 4.96 \\
\hline Clearing level 1 & 1 & $1 \cdot 79$ & 1.95 \\
\hline \multirow{2}{*}{ Casting level 2} & 2 & $4 \cdot 91$ & $5 \cdot 00$ \\
\hline & 1 & $3 \cdot 17$ & $3 \cdot 17$ \\
\hline \multirow[t]{2}{*}{ Clearing level 2} & 2 & $2 \cdot 48$ & 2.95 \\
\hline & 1 & $3 \cdot 37$ & $3 \cdot 57$ \\
\hline \multirow[t]{3}{*}{ Casting level 3} & 3 & $4 \cdot 86$ & 4.95 \\
\hline & 2 & $3 \cdot 62$ & 4.06 \\
\hline & 1 & 4.07 & $4 \cdot 56$ \\
\hline \multirow[t]{3}{*}{ Clearing level 3} & 3 & $2 \cdot 58$ & $2 \cdot 87$ \\
\hline & 2 & $2 \cdot 68$ & $3 \cdot 84$ \\
\hline & 1 & $3 \cdot 42$ & $3 \cdot 91$ \\
\hline \multirow[t]{2}{*}{ Striking level 1} & 3 & $1 \cdot 78$ & $1 \cdot 83$ \\
\hline & 2 & $1 \cdot 44$ & 1.93 \\
\hline \multirow[t]{3}{*}{ Casting level 4} & 4 & 5.05 & 4.90 \\
\hline & 3 & $2 \cdot 18$ & $2 \cdot 13$ \\
\hline & 2 & $2 \cdot 28$ & $2 \cdot 23$ \\
\hline \multirow[t]{3}{*}{ Clearing level 4} & 4 & $2 \cdot 43$ & $2 \cdot 72$ \\
\hline & 3 & $2 \cdot 57$ & $2 \cdot 87$ \\
\hline & 2 & $2 \cdot 62$ & $2 \cdot 72$ \\
\hline \multirow[t]{2}{*}{ Striking level 2} & 4 & $1 \cdot 78$ & $2 \cdot 23$ \\
\hline & 3 & $1 \cdot 88$ & $2 \cdot 13$ \\
\hline \multirow[t]{3}{*}{ Casting level 5} & 5 & 4.95 & $4 \cdot 85$ \\
\hline & 4 & $2 \cdot 23$ & $3 \cdot 47$ \\
\hline & 3 & $2 \cdot 28$ & $3 \cdot 12$ \\
\hline \multirow[t]{3}{*}{ Clearing level 5} & 5 & $2 \cdot 08$ & $2 \cdot 72$ \\
\hline & 4 & $2 \cdot 33$ & $2 \cdot 97$ \\
\hline & 3 & $3 \cdot 32$ & $3 \cdot 12$ \\
\hline \multirow[t]{2}{*}{ Striking level 3} & 5 & $1 \cdot 78$ & $2 \cdot 18$ \\
\hline & 4 & $1 \cdot 88$ & $2 \cdot 33$ \\
\hline \multirow[t]{3}{*}{ Casting level 6} & 6 & $5 \cdot 00$ & $5 \cdot 00$ \\
\hline & 5 & $2 \cdot 87$ & $4 \cdot 50$ \\
\hline & 4 & $2 \cdot 03$ & $3 \cdot 02$ \\
\hline
\end{tabular}

Table 1. Loads on corner and border spans at each construction stage

and 8(b) show a completely modelled section of the building and a standard slab, respectively.

The geometric characteristics of the elements in the experimental model were as described in Section 3. The construction process was modelled as described in the phases shown in Figures 2 to 5. The hypotheses adopted for the FEM simulation can be found in Alvarado et al. (2010).

\subsection{Finite elements and meshing}

The concrete floor slabs and formwork boards were modelled using the two-dimensional Shell63 element (Ansys, 2006b). Steel

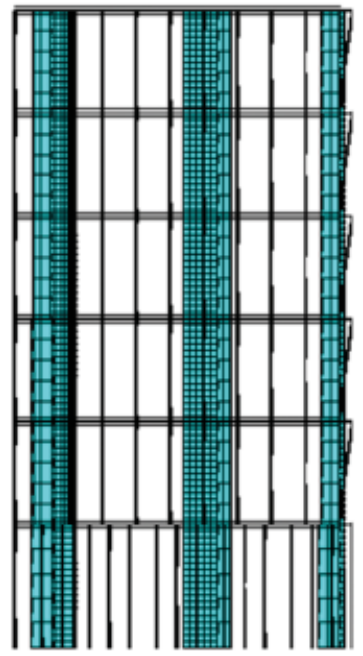

(a)

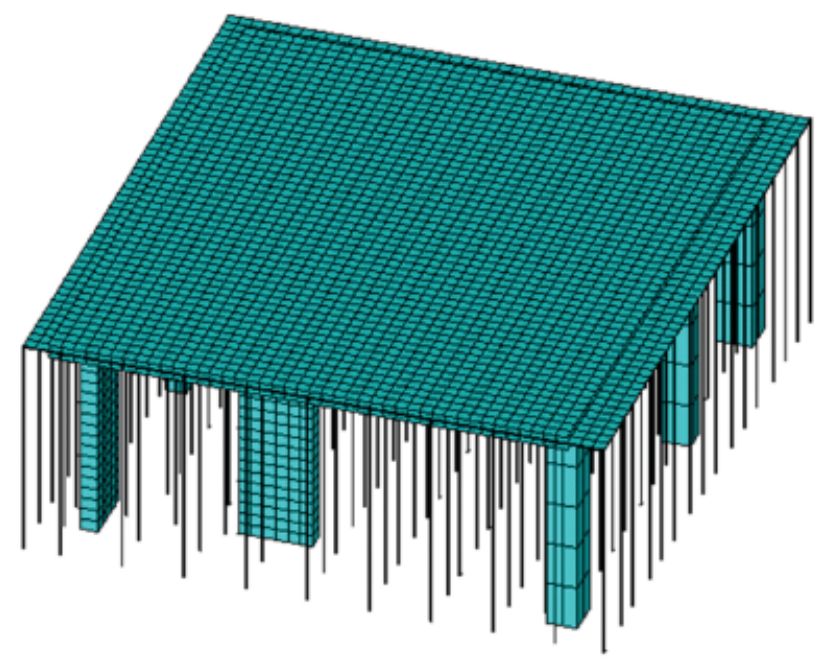

(b)

Figure 8. Finite-element model: (a) cross-section;

(b) representative slab

shores were modelled by the one-dimensional two-node Link10 (Ansys, 2006b) and the concrete columns were modelled by Beam188 (Ansys, 2006b) and Shell63 (Ansys, 2006b) elements, the latter being used for wide columns. The slab mesh size is conditioned by the slab dimensions and the distribution of the formwork and shoring elements. A $0.20 \times 0.20 \mathrm{~m}^{2}$ slab finiteelement mesh size provided an appropriate degree of approximation. For formwork elements and wide columns, the mesh size was also $0.20 \times 0.20 \mathrm{~m}^{2}$. The mesh size for the remaining concrete columns was $0.61 \mathrm{~m}$.

\subsection{Simulating the construction process}

To simulate the building process using the FEM, an evolving structure model must be considered that allows the supporting 
elements (shores and formwork) and the concrete mechanical characteristics to change over time. The maturity method was used to determine the evolution of the concrete slabs' elastic modulus.

The software used (Ansys, 2006a) allows an evolving calculation to be carried out by different load steps. Each load step corresponds to one of the building phases. The different load steps considered are shown in Figures 2 to 5 .

\subsection{Results}

FEM results were obtained for the shores coinciding with those instrumented during the construction process. The results ob- tained in each load step corresponding to the different phases are listed in Table 2. For each slab, the following values are shown (FEM analysis 1).

(a) Average load in the corner span $\left(\bar{Q}_{\text {FEMlcorner }}\right)$ on shores $\left(\mathrm{kN} / \mathrm{m}^{2}\right)$. This value was obtained from the FEM shores of the corner span corresponding to the instrumented shores in the experimental study.

(b) Average load in the border span $\left(\bar{Q}_{\text {FEMlborder }}\right)$ on shores $\left(\mathrm{kN} / \mathrm{m}^{2}\right)$. This value was obtained from the FEM shores of the border span corresponding to the instrumented shores in the experimental study.

\begin{tabular}{|c|c|c|c|c|c|c|}
\hline \multirow[t]{2}{*}{ Load step } & \multirow[t]{2}{*}{ Stage of construction } & \multirow[t]{2}{*}{ Level } & \multicolumn{4}{|c|}{ Load: kN/m² } \\
\hline & & & $\bar{Q}_{\text {fEM1corner }}$ & $\bar{Q}_{\mathrm{FEM} 2 \text { corner }}$ & $\bar{Q}_{\text {FEM1 border }}$ & $\bar{Q}_{\mathrm{FEM} 2 \text { border }}$ \\
\hline 1 & Casting level 1 & 1 & 4.96 & $4 \cdot 86$ & 4.95 & $4 \cdot 76$ \\
\hline 2 & Clearing level 1 & 1 & $1 \cdot 84$ & $2 \cdot 14$ & $2 \cdot 20$ & $2 \cdot 21$ \\
\hline \multirow[t]{2}{*}{3} & Casting level 2 & 2 & $4 \cdot 85$ & $4 \cdot 87$ & 4.97 & $4 \cdot 91$ \\
\hline & & 1 & 3.69 & $4 \cdot 27$ & $3 \cdot 86$ & $4 \cdot 50$ \\
\hline \multirow[t]{2}{*}{4} & Clearing level 2 & 2 & $1 \cdot 77$ & 1.97 & $2 \cdot 12$ & $2 \cdot 02$ \\
\hline & & 1 & $2 \cdot 70$ & $3 \cdot 19$ & $2 \cdot 91$ & $3 \cdot 46$ \\
\hline \multirow[t]{3}{*}{5} & Casting level 3 & 3 & $4 \cdot 85$ & $4 \cdot 87$ & 4.97 & $4 \cdot 91$ \\
\hline & & 2 & $3 \cdot 50$ & 3.90 & $4 \cdot 15$ & $4 \cdot 08$ \\
\hline & & 1 & $3 \cdot 53$ & $4 \cdot 23$ & $3 \cdot 88$ & $4 \cdot 61$ \\
\hline \multirow[t]{3}{*}{6} & Clearing level 3 & 3 & $1 \cdot 79$ & 1.97 & $2 \cdot 13$ & $2 \cdot 07$ \\
\hline & & 2 & $2 \cdot 58$ & $2 \cdot 94$ & $3 \cdot 12$ & $3 \cdot 13$ \\
\hline & & 1 & $3 \cdot 16$ & $3 \cdot 74$ & $3 \cdot 45$ & 4.08 \\
\hline \multirow[t]{2}{*}{7} & Striking level 1 & 3 & $1 \cdot 51$ & 1.49 & 1.63 & $1 \cdot 51$ \\
\hline & & 2 & $1 \cdot 71$ & $1 \cdot 58$ & $1 \cdot 75$ & $1 \cdot 59$ \\
\hline \multirow[t]{3}{*}{8} & Casting level 4 & 4 & $4 \cdot 85$ & $4 \cdot 87$ & 4.97 & $4 \cdot 91$ \\
\hline & & 3 & $3 \cdot 16$ & $3 \cdot 28$ & $3 \cdot 56$ & $3 \cdot 40$ \\
\hline & & 2 & $2 \cdot 37$ & $2 \cdot 32$ & $2 \cdot 52$ & $2 \cdot 40$ \\
\hline \multirow[t]{3}{*}{9} & Clearing level 4 & 4 & $1 \cdot 75$ & 1.95 & $2 \cdot 11$ & 1.99 \\
\hline & & 3 & $2 \cdot 29$ & $2 \cdot 41$ & $2 \cdot 60$ & $2 \cdot 55$ \\
\hline & & 2 & $2 \cdot 13$ & $2 \cdot 03$ & $2 \cdot 22$ & 2.09 \\
\hline \multirow[t]{2}{*}{10} & Striking level 2 & 4 & 1.59 & $1 \cdot 70$ & $1 \cdot 86$ & $1 \cdot 77$ \\
\hline & & 3 & $1 \cdot 74$ & $1 \cdot 71$ & 1.85 & $1 \cdot 76$ \\
\hline \multirow[t]{3}{*}{11} & Casting level 5 & 5 & 4.92 & $4 \cdot 80$ & 4.99 & 4.90 \\
\hline & & 4 & $3 \cdot 22$ & 3.49 & $3 \cdot 79$ & 3.64 \\
\hline & & 3 & $2 \cdot 39$ & $2 \cdot 44$ & $2 \cdot 61$ & $2 \cdot 57$ \\
\hline \multirow[t]{3}{*}{12} & Clearing level 5 & 5 & $1 \cdot 76$ & 1.95 & $2 \cdot 11$ & 1.99 \\
\hline & & 4 & $2 \cdot 37$ & $2 \cdot 63$ & $2 \cdot 83$ & $2 \cdot 81$ \\
\hline & & 3 & $2 \cdot 15$ & $2 \cdot 16$ & $2 \cdot 32$ & $2 \cdot 27$ \\
\hline \multirow[t]{2}{*}{13} & Striking level 3 & 5 & $1 \cdot 60$ & 1.69 & 1.84 & $1 \cdot 75$ \\
\hline & & 4 & 1.80 & 1.88 & $2 \cdot 02$ & 1.96 \\
\hline \multirow[t]{3}{*}{14} & Casting level 6 & 6 & $4 \cdot 85$ & $4 \cdot 87$ & 4.97 & $4 \cdot 91$ \\
\hline & & 5 & $3 \cdot 25$ & 3.49 & $3 \cdot 78$ & 3.65 \\
\hline & & 4 & $2 \cdot 45$ & $2 \cdot 62$ & $2 \cdot 78$ & $2 \cdot 77$ \\
\hline
\end{tabular}

Table 2. Results of the finite-element model 
Results were also obtained in each load step, corresponding to the different construction phases, for all the shores placed under the spans analysed (FEM analysis 2). For each slab Table 2 shows

(a) the average load in the corner span $\left(\bar{Q}_{\text {FEM2corner }}\right)$ on shores $\left(\mathrm{kN} / \mathrm{m}^{2}\right)$

(b) the average load in the border span $\left(\bar{Q}_{\text {FEM2border }}\right.$ on shores $\left(\mathrm{kN} / \mathrm{m}^{2}\right)$.

\subsection{Comparison of experimental and FEM results}

Table 3 compares the average shore load values obtained on the building site $\left(\bar{Q}_{\text {exp }}\right)$ and the corresponding values from the FEM $\left(\bar{Q}_{\mathrm{FEM} 1}\right)$ obtained from the load on the shores equivalent to those from which readings were taken on site. It can be seen that the

\begin{tabular}{|c|c|c|c|}
\hline Stage of construction & Level & $\frac{\bar{Q}_{\text {expcorner }}}{\bar{Q}_{\text {FEM1corner }}}$ & $\frac{\bar{Q}_{\text {expborder }}}{\bar{Q}_{\text {FEM1border }}}$ \\
\hline Casting level 1 & 1 & 1.00 & 1.00 \\
\hline Clearing level 1 & 1 & 0.97 & 0.89 \\
\hline \multirow[t]{2}{*}{ Casting level 2} & 2 & $1 \cdot 01$ & $1 \cdot 01$ \\
\hline & 1 & $0 \cdot 86$ & 0.82 \\
\hline \multirow[t]{2}{*}{ Clearing level 2} & 2 & 1.40 & $1 \cdot 39$ \\
\hline & 1 & $1 \cdot 25$ & $1 \cdot 23$ \\
\hline \multirow[t]{3}{*}{ Casting level 3} & 3 & 1.00 & $1 \cdot 00$ \\
\hline & 2 & 1.03 & 0.98 \\
\hline & 1 & $1 \cdot 15$ & $1 \cdot 18$ \\
\hline \multirow[t]{3}{*}{ Clearing level 3} & 3 & 1.44 & $1 \cdot 35$ \\
\hline & 2 & $1 \cdot 04$ & $1 \cdot 23$ \\
\hline & 1 & 1.09 & $1 \cdot 14$ \\
\hline \multirow[t]{2}{*}{ Striking level 1} & 3 & $1 \cdot 19$ & $1 \cdot 13$ \\
\hline & 2 & 0.84 & $1 \cdot 11$ \\
\hline \multirow[t]{3}{*}{ Casting level 4} & 4 & 1.04 & 0.99 \\
\hline & 3 & 0.69 & 0.60 \\
\hline & 2 & 0.96 & 0.89 \\
\hline \multirow[t]{3}{*}{ Clearing level 4} & 4 & $1 \cdot 39$ & $1 \cdot 29$ \\
\hline & 3 & $1 \cdot 13$ & $1 \cdot 11$ \\
\hline & 2 & $1 \cdot 24$ & $1 \cdot 23$ \\
\hline \multirow[t]{2}{*}{ Striking level 2} & 4 & $1 \cdot 12$ & $1 \cdot 20$ \\
\hline & 3 & 1.09 & $1 \cdot 15$ \\
\hline \multirow[t]{3}{*}{ Casting level 5} & 5 & $1 \cdot 01$ & 0.97 \\
\hline & 4 & 0.69 & 0.92 \\
\hline & 3 & 0.96 & $1 \cdot 20$ \\
\hline \multirow[t]{3}{*}{ Clearing level 5} & 5 & $1 \cdot 18$ & $1 \cdot 29$ \\
\hline & 4 & 0.98 & 1.05 \\
\hline & 3 & $1 \cdot 55$ & $1 \cdot 35$ \\
\hline \multirow[t]{2}{*}{ Striking level 3} & 5 & $1 \cdot 12$ & $1 \cdot 19$ \\
\hline & 4 & 1.05 & $1 \cdot 15$ \\
\hline \multirow[t]{3}{*}{ Casting level 6} & 6 & 1.03 & $1 \cdot 01$ \\
\hline & 5 & 0.89 & $1 \cdot 20$ \\
\hline & 4 & 0.83 & 1.09 \\
\hline Mean & - & 1.07 & $1 \cdot 10$ \\
\hline Standard deviation & - & $0 \cdot 19$ & $0 \cdot 17$ \\
\hline
\end{tabular}

Table 3. Comparison of experimental and FEM results average $\bar{Q}_{\text {exp }} / \bar{Q}_{\text {FEM1 }}$ ratio of all operations is 1.07 (standard deviation $0 \cdot 19)$ for the corner span and $1.10(0.17$ standard deviation) for the border.

The most significant differences are observed in the casting and clearing operations of slab 4 and in the clearing of slab 5. These variations were due to changes from normal building procedures that were required in these operations. When slab 4 was being poured, some of the level 3 shores were temporarily removed to permit the passage of construction materials, which caused a reduced load on slab 2 when slab 4 was poured. During the clearing of slab 5, the slab 3 shores were adjusted to correct the maladjustment of the shores connected to one of the straining pieces, which led to increased load on the slab 3 shores. These unforeseen operations carried out during the construction process significantly modified the expected transmitted loads between slabs and shores.

\subsection{Comparison of results from straining piece shores with those obtained from total shores in a span in the FEM}

From the FEM, results can be extracted from both the shores of the monitored straining piece and from the total shores contained in a span. Both results can be compared to check whether the results obtained from the shores of the straining piece are representative of the complete span.

As can be seen in Table 4 , the average $\bar{Q}_{\mathrm{FEM} 1} / \bar{Q}_{\mathrm{FEM} 2}$ ratio of all operations in the corner span is 0.95 (standard deviation 0.07). The average for the border span is 1.01 , with an identical standard deviation. From these two results, it can be concluded that the average load on the shores of the straining piece can be assumed to be the average value for the shores of the entire span in both locations.

\section{Simplified methods}

In order to simulate the clearing process, it is necessary that the simplified method considers the real stiffness of the shores, because partial striking is just a reduction of that stiffness. The following three simplified methods that consider the real stiffness of shores and slabs were used.

(a) The improved simplified method of Duan and Chen (1995) considers the following assumptions.

(i) The slabs are considered to have elastic behaviour and variations in their stiffness over time are considered.

(ii) Shores are simulated as elastic elements with finite stiffness.

(iii) The effects of shrinkage and creep are not included.

(iv) The loads on shoring are considered to be evenly distributed over the slabs.

(v) Deformation of the shores located at the centre of the slab is equal to the average deformation of all the shores on the same level. 


\begin{tabular}{|c|c|c|c|}
\hline Stage of construction & Level & $\frac{\bar{Q}_{\text {FEM1corner }}}{\bar{Q}_{\text {FEM2corner }}}$ & $\frac{\bar{Q}_{\mathrm{FEM} 1 \text { border }}}{\bar{Q}_{\mathrm{FEM} 2 \text { border }}}$ \\
\hline Casting level 1 & 1 & 1.06 & 1.08 \\
\hline Clearing level 1 & 1 & 0.86 & 0.99 \\
\hline \multirow[t]{2}{*}{ Casting level 2} & 2 & 1.00 & $1 \cdot 01$ \\
\hline & 1 & 0.86 & 0.86 \\
\hline \multirow[t]{2}{*}{ Clearing level 2} & 2 & 0.90 & $1 \cdot 05$ \\
\hline & 1 & 0.84 & 0.84 \\
\hline \multirow[t]{3}{*}{ Casting level 3} & 3 & 1.00 & 1.01 \\
\hline & 2 & 0.90 & 1.02 \\
\hline & 1 & 0.84 & 0.84 \\
\hline \multirow[t]{3}{*}{ Clearing level 3} & 3 & 0.91 & 1.03 \\
\hline & 2 & 0.88 & 1.00 \\
\hline & 1 & $0 \cdot 84$ & 0.84 \\
\hline \multirow[t]{2}{*}{ Striking level 1} & 3 & 1.01 & 1.08 \\
\hline & 2 & 1.08 & $1 \cdot 10$ \\
\hline \multirow[t]{3}{*}{ Casting level 4} & 4 & 1.00 & 1.01 \\
\hline & 3 & 0.96 & $1 \cdot 05$ \\
\hline & 2 & 1.02 & 1.05 \\
\hline \multirow[t]{3}{*}{ Clearing level 4} & 4 & 0.90 & 1.06 \\
\hline & 3 & 0.95 & 1.02 \\
\hline & 2 & 1.05 & 1.06 \\
\hline \multirow[t]{2}{*}{ Striking level 2} & 4 & 0.94 & 1.05 \\
\hline & 3 & 1.02 & $1 \cdot 05$ \\
\hline \multirow[t]{3}{*}{ Casting level 5} & 5 & 1.02 & 1.02 \\
\hline & 4 & 0.92 & 1.04 \\
\hline & 3 & 0.98 & $1 \cdot 01$ \\
\hline \multirow[t]{3}{*}{ Clearing level 5} & 5 & 0.90 & 1.06 \\
\hline & 4 & 0.90 & 1.01 \\
\hline & 3 & 1.00 & 1.02 \\
\hline \multirow[t]{2}{*}{ Striking level 3} & 5 & 0.94 & $1 \cdot 05$ \\
\hline & 4 & 0.96 & 1.03 \\
\hline \multirow[t]{3}{*}{ Casting level 6} & 6 & 1.00 & 1.01 \\
\hline & 5 & 0.93 & 1.03 \\
\hline & 4 & 0.94 & $1 \cdot 01$ \\
\hline Mean & - & 0.95 & $1 \cdot 01$ \\
\hline Standard deviation & - & 0.07 & 0.07 \\
\hline
\end{tabular}

(iii) The model is incremental and considers cumulative loads and displacements during the different stages of construction.

(iv) Shores are elastic elements with finite stiffness.

(v) The loads transmitted from shores to slabs are uniformly distributed.

(vi) Average slab deformation coincides with the average deformation of the supporting shores.

(vii) Different slab boundary conditions are considered (internal, end, corner spans, etc.) and deformability is estimated by the Scanlon and Murray (1982) method.

(viii) Creep and shrinkage effects are not considered.

The average load on shores obtained using these methods was compared with the experimental readings and the results from the numerical model.

\subsection{Results and comparison}

All three methods were applied to both types of span studied, one corner and one border. As indicated in Section 4.5, the average load on the shores of the entire span can be taken as the average load on the shores of the studied straining piece. The results obtained from the experimental readings $\left(\bar{Q}_{\text {exp }}\right)$ can thus be used to compare with those obtained from the simplified methods.

Figure 9 shows, for the corner span, a comparison between the average load on shores obtained in each stage during the construction of the building $\left(\bar{Q}_{\text {exp }}\right)$ and the average load on shores obtained with the improved simplified method of Duan and Chen $\left(\bar{Q}_{\mathrm{D \& C}}\right)$, the simplified method of Fang et al. $\left(\bar{Q}_{\text {Fang }}\right)$ and the new simplified procedure of Calderón et al. $\left(\bar{Q}_{\mathrm{NSP}}\right)$. Figure 10 shows the same comparison for the border span.

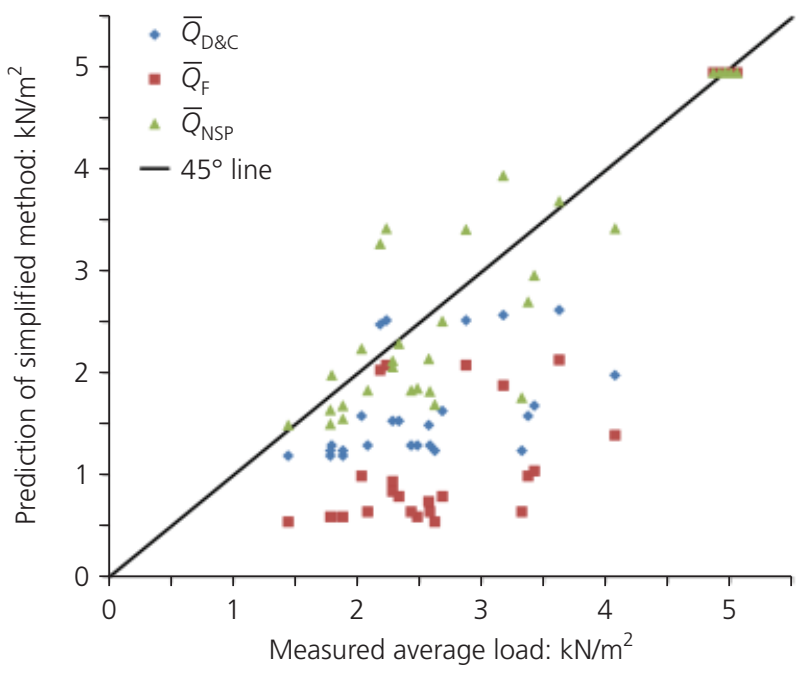

Figure 9. Comparison between average load on shores obtained with the simplified methods and experimental readings for the corner span 


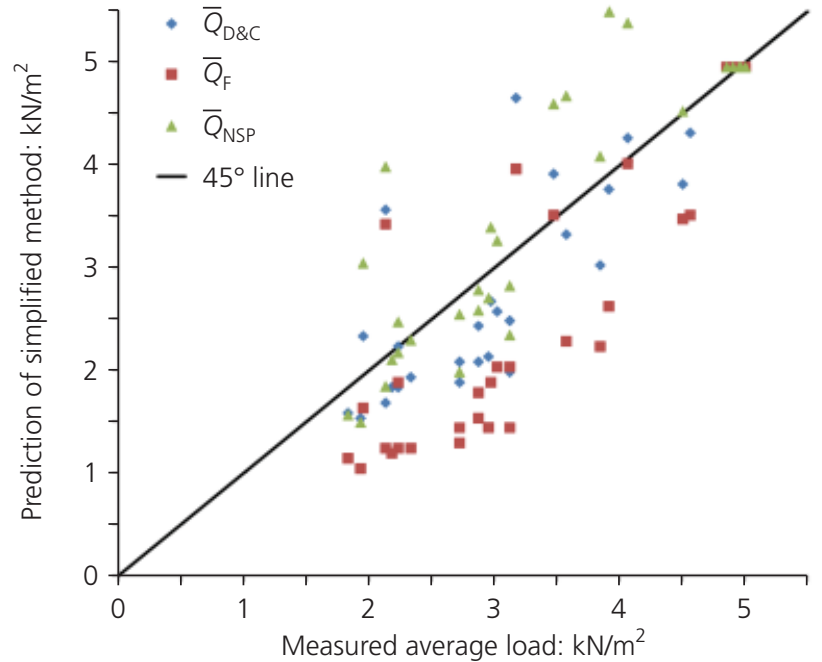

Figure 10. Comparison between average load on shores, for the border span, obtained with the simplified methods and experimental readings

Figure 11 shows, for the corner span, a comparison between the average load on shores obtained with the numerical model $\left(\bar{Q}_{\mathrm{FEM} 2}\right)$ and those obtained with the simplified methods. Figure 12 shows the same comparison for the border span.

As shown in Table 5, for the corner span, the method that has a better fit with both the experimental readings and the numerical results is the new simplified procedure of Calderón et al. It can be seen that the ratio $\bar{Q}_{\text {expcorner }} / \bar{Q}_{\text {NSPcorner }}$ of the average shore loads for all construction phases is 1.09 (standard deviation 0.23 )

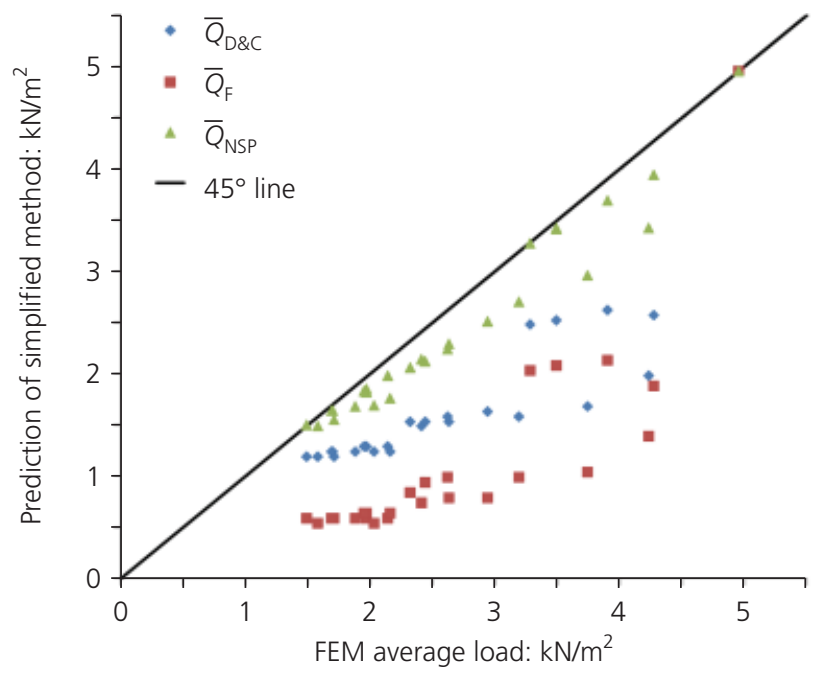

Figure 11. Comparison of average load on shores obtained by the simplified methods and the numerical model for the corner span

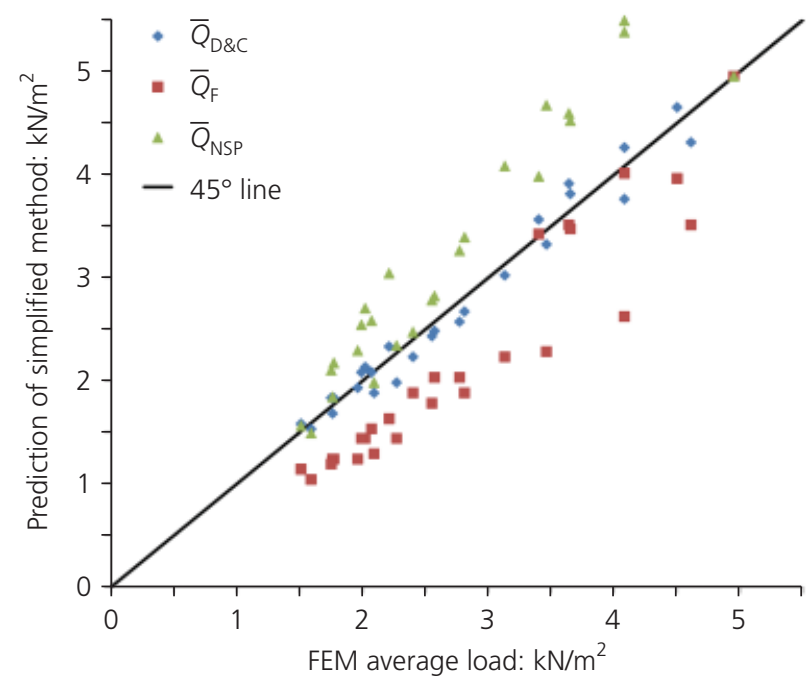

Figure 12. Comparison of average load on shores obtained by the simplified methods and the numerical model for the border span

and the $\bar{Q}_{\text {FEM2corner }} / \bar{Q}_{\text {NSPcorner }}$ ratio of the average shore loads for all construction phases is 1.08 (standard deviation 0.08).

In the case of the border span, good fits are obtained with both the improved simplified method of Duan and Chen (1995) and the new simplified procedure of Calderón et al. (2011).

\section{Conclusion}

This paper has described experimental measurements carried out on a building under construction in Madrid. The readings obtained provided information on how loads are transmitted between slabs and shores in the course of a SCS process. The results showed that the load transmission varied according to the type of span studied, due to the different ways in which their deformability and/or stiffness are affected by their different geometries and boundary conditions.

In the course of the building work it became necessary to alter the normal procedures in order to solve certain practical problems, and these unforeseen operations had a notable effect on the expected slab-shore load transmission.

The building was simulated using a non-linear evolving FEM calculation that considered the construction process used and the evolution of concrete characteristics over time. The FEM results showed a satisfactory fit with the readings obtained.

The results from shores connected to the monitored straining piece and also from the complete set of shores in the span were extracted from the FEM. Comparison of both results showed that the average load on the straining piece can be assumed to be similar to the total load of the shores of the span. 


\begin{tabular}{llcccc}
\hline Span & Method & $\begin{array}{c}\text { Mean } \\
\bar{Q}_{\text {exp }} / \bar{Q}_{\text {SM }}\end{array}$ & $\begin{array}{c}\text { Standard } \\
\text { deviation }\end{array}$ & $\begin{array}{c}\text { Mean } \\
\bar{Q}_{\text {FEM2 }} / \bar{Q}_{\text {SM }}\end{array}$ & $\begin{array}{c}\text { Standard } \\
\text { deviation }\end{array}$ \\
\hline Corner & Duan and Chen & 1.49 & 0.43 & 1.48 & 0.32 \\
& Fang et al. & 2.59 & 1.17 & 2.53 & 0.91 \\
\multirow{3}{*}{ Border } & Calderón et al. & 1.09 & 0.23 & 1.08 & 0.08 \\
& Duan and Chen & 1.13 & 0.20 & 1.01 & 0.05 \\
& Fang et al. & 1.46 & 0.41 & 0.29 & 0.21 \\
& Calderón et al. & 0.97 & 0.20 & 0.10
\end{tabular}

Table 5. Comparison of experimental and numerical results with the results of the simplified methods (SMs) of Duan and Chen (1995), Fang et al. (2001a) and Calderón et al. (2011)

The readings and the results from the numerical model were also compared with those of simplified methods. For the corner span, the method that had a better fit with the measured and numerical results was the new simplified procedure proposed by Calderón et al. (2011). For the border span, both the improved simplified method of Duan and Chen (1995) and the new simplified procedure of Calderón et al. (2011) showed good degrees of fit.

\section{Acknowledgements}

The authors would like to express their gratitude to the companies SACYR and Encofrados J. Alsina for their invaluable cooperation.

\section{REFERENCES}

Alvarado YA (2009) Estudio experimental y numérico de la construcción de forjados hormigonados in situ mediante procesos de cimbrado, clareado y descimbrado de plantas consecutivas. $\mathrm{PhD}$ thesis, Universidad Politècnica de Valencia, Valencia, Spain. See http.//hdl.handle.net/10251/ 7285 (accessed 24/02/2010) (in Spanish).

Alvarado YA, Calderón PA, Adam JM, Payá IJ, Pellicer T and Pallares FJ (2009) An experimental study into the evolution of loads on shores and slabs during construction of multistorey buildings using partial striking. Engineering Structures 31(9): 2132-2140.

Alvarado YA, Calderón PA, Gasch I and Adam JM (2010) A numerical study into the evolution of loads on shores and slabs during construction of multistorey buildings. Comparison of partial striking with other techniques. Engineering Structures 32(10): 3093-3102.

Ansys (2006a) Ansys 11.0 Theory Reference. Ansys Inc., Canonsburg, PA, USA.

Ansys (2006b) Ansys 11.0 Element reference. Ansys Inc., Canonsburg, PA, USA.

Calderón PA, Alvarado YA and Adam JM (2011) A new simplified procedure to estimate loads on slabs and shoring during the construction of multistorey buildings. Engineering Structures 33(5): 1565-1575.
Duan MZ and Chen WF (1995) Improved Simplified Method for Slab and Shore Load Analysis During Construction. Purdue University, West Lafayette, IN, USA, Project report CE-STR95-24.

Fang DP, Zhu HY, Geng CD and Liu XL (2001a) Floor load distribution in reinforced concrete buildings during construction. ACI Structural Journal 98(2): 149-156.

Fang DP, Zhu HY, Geng CD and Liu XL (2001b) On-site measurements of structural characteristics of reinforced concrete buildings during construction. ACI Structural Journal 98(2): 157-163.

Fang DP, Xi H, Wang X, Zhang Ch and Zhao T (2009a) Load distribution assessment of reinforced concrete buildings during construction with structural characteristic parameter approach. Tsinghua Science and Technology 14(6): 746755.

Fang DP, Xi H, Wang X and Zhang Ch (2009b) Influences of shrinkage, creep, and temperature on the load distributions in reinforced concrete buildings during construction. Tsinghua Science and Technology 14(6): 756764.

Grundy P and Kabaila A (1963) Construction loads on slabs with shored formwork in multistorey buildings. ACI Journal Proceedings 60(12): 1729-1738.

Liu XL, Chen WF and Bowman MD (1985) Construction load analysis for concrete structures. Journal of Structural Engineering 111(5): 1019-1036.

Moragues JJ, Catalá J, Salort V and Sirvent PL (1991) Transmisión de cargas entre forjados, durante el proceso constructivo, Medidas realizadas en obra. Hormigón y Acero 178(1): 37-47 (in Spanish).

Moragues JJ, Catalá J and Pellicer E (1996) An analysis of concrete framed structures during the construction process. Concrete International 18(11): 44-48.

Pintado XC and Carlton RJ (2007) Modelling prop loads during concrete slab construction. Structures and Buildings 160(4): 221-229.

Rosowsky DV, Philbrick TW and Huston DR (1997) 
Observations from shore load measurements during concrete construction. Journal of Performance of Constructed Facilities 11(1): 18-23.

Scanlon A and Murray DB (1982) Practical Calculation of Twoway Slab Deflection. Concrete International, Design and
Construction, American Concrete Institute, Detroit, MI, USA.

Stivaros P and Halvorsen G (1991) Equivalent frame analysis of concrete buildings during construction. Concrete International 13(8): 57-62

\section{WHAT DO YOU THINK?}

To discuss this paper, please email up to 500 words to the editor at journals@ice.org.uk. Your contribution will be forwarded to the author(s) for a reply and, if considered appropriate by the editorial panel, will be published as a discussion in a future issue of the journal.

Proceedings journals rely entirely on contributions sent in by civil engineering professionals, academics and students. Papers should be 2000-5000 words long (briefing papers should be 1000-2000 words long), with adequate illustrations and references. You can submit your paper online via www.icevirtuallibrary.com/content/journals, where you will also find detailed author guidelines. 